\title{
The antiperinuclear factor: II. A light microscopical and immunofluorescence study on the antigenic substrate
}

\author{
J. W. SMIT, INEZ R. J. M. SONDAG-TSCHROOTS, C. AAIJ, \\ T. E. W. FELTKAMP, AND THEA M. FELTKAMP-VROOM
}

From the Department of Immunohistopathology and Department of Autoimmune Diseases, Central Laboratory of the Netherlands Red Cross Blood Transfusion Service, and the Laboratory of Experimental and Clinical Immunology, University of Amsterdam, The Netherlands

SUMMARY The antigenic substrate of the antiperinuclear factor (APF) in human buccal mucosa cells was studied by light microscopy, cytochemistry, and the immunofluorescence technique (IFT). The cytoplasmic granules against which the APF is directed stained basophilic in light-microscopical staining techniques. The granules did not show a positive reaction product by techniques in which special chemical components are stained, and no activity of lysosomal enzymes could be identified. The use of autoantibodies and other antisera directed to distinct tissues, tissue components, or macromolecules did not resolve the character of the antigenic granules. In addition it was shown that human vaginal epithelial cells and cryostat sections of human and rabbit buccal and oesophageal mucosa incubated with APF-positive sera showed the same fluorescent granules in the IFT as human buccal mucosa cells. Cryostat sections of rabbit buccal and oesophageal mucosa were tested as an alternative substrate in the APF test. Since the specificity as well as the sensitivity decreased when these sections were used as a substrate, they are not suitable for diagnostic purposes.

In a previous study ${ }^{1}$ the diagnostic significance of the antiperinuclear factor (APF) was re-evaluated. This factor consists of antibodies reacting with cytoplasmic granules in human cheek epithelial cells. It was demonstrated that the APF revealed a high sensitivity for rheumatoid arthritis (RA) combined with a good specificity, as the APF frequency in patients with other autoimmune diseases, degenerative joint disease, and healthy subjects was low. When the APF test was used in combination with the rheumatoid factor tests, the number of seronegative RA patients decreased remarkably.

Since in other studies on this subject ${ }^{2-4}$ the origin of cytoplasmic granules was suggested to be the keratohyaline granules in which the antigen of unknown chemical nature is present, we performed a morphological and immunohistochemical study on the antigenic substrate of the APF. In addition

Accepted for publication 17 July 1979

Correspondence to J. W. Smit, Division of Haematology, Department of Medicine, University of Groningen, Oostersingel 59, The Netherlands. other substrates were tested for their antigenicity. In this paper we report the results obtained by light microscopy and by the immunofluorescence technique (IFT). The results of an ultrastructural study on the antigenic substrate for the APF will be published separately (Smit and Feltkamp-Vroom, submitted for publication).

\section{Materials and methods}

\section{ANTIGENIC SUBSTRATES}

Epithelial cells from human oral mucosa were used as substrate in the serological study. Further human vaginal epithelial cells and cryostat sections of oral and oesophageal mucosa from several species were used as a substrate.

Normal human buccal epithelial cells were scraped from the inner side of the cheek with a piece of foam plastic. To obtain a cell suspension the foam plastic was rinsed in phosphate buffered saline, pH $7 \cdot 4$ (PBS).

Human vaginal epithelial cells were obtained from 
adults during routine screenings, or from newborn babies at the department of gynaecology and obstetrics. After scraping the cells were suspended in PBS.

The oral and vaginal epithelial cells suspensions were washed 3 times with PBS. A cell suspension was made in PBS and the cells were transferred dropwise to microscope slides. After air drying at room temperature for 15 minutes the cell preparations could be used as a substrate in the IFT.

Biopsies of oral mucosa from man, rabbit, rat, cow, and pig and biopsies of oesophageal mucosa from man and rabbit were frozen in liquid nitrogen. $4 \mu \mathrm{m}$ sections were cut in a cryostat and used as substrate in the IFT.

\section{DETECTION OF THE APF BY THE}

IMMUNOFLUORESCENCE TECHNIQUE

The antigenic substrates were fixed in acetone (10 minutes) and incubated for 90 minutes with the sera of the RA patients which were known to be positive for APF or with the sera of healthy controls. The sera were diluted $1 / 5$ in PBS. After washing in PBS (30 minutes) the preparations were incubated with fluorescein isothiocyanate (FITC)conjugated antihuman $\mathrm{Ig}$ or antihuman $\mathrm{IgG}$ antibodies for 30 minutes. The FITC-labelled antisera were prepared in our laboratory: Horse antihuman Ig, Lot nr. PH-17-4-F6, dilution 1/60; Rabbit antihuman IgG, lot $\mathrm{nr}$. $\mathrm{KH}-16-103-\mathrm{F} 1$, dilution $1 / 80$.

Finally the preparations could be incubated with a solution of ethidium bromide $(100 \mu \mathrm{g} / \mathrm{ml})$ in PBS for 5 minutes as nuclear counterstain washed in PBS and mounted in a glycerin-PBS solution (1:1). Slides were read in a Leitz Orthoplan fluorescence microscope.

\section{LIGHT MICROSCOPY AND CYTOCHEMISTRY}

Sediments of human buccal mucosa cells were stained with haematoxylin and azophloxin (HA), May-Grünwald-Giesma (MGG), toluidin, Sudan black, oil red-O, periodic acid Schiff (PAS), methylgreen-pyronin (MGP), Feulgen, Congo red, Alcian blue (pH 1.0 and $2 \cdot 5)$, azur $\mathrm{A}(\mathrm{pH} 0 \cdot 5,1 \cdot 5,3 \cdot 5$, and 4.0), and dinaphthyldihydroxy-disulfide (DDD) according to Barnett and Seligman. ${ }^{5}$ In addition the cells were reacted for the enzymes acid phosphatase as described by $\mathrm{Li}$ et al., ${ }^{6}$ nonspecific esterase as described by Löffler et al., ${ }^{7}$ and peroxidase according to Graham and Karnovsky. ${ }^{8}$

Biopsies of oral mucosa were fixed in phosphate buffered formalin (pH 7.2), dehydrated, and embedded in Paraplast. 2-4 $\mu \mathrm{m}$ sections were stained with HA.
Sediments of vaginal epithelial cells were stained with HA and MGG.

ANTISERA DIRECTED TO SPECIAL COMPONENTS Sera of several patients with autoimmune diseases were used in the indirect IFT. Human buccal epithelial cells were used as the antigenic substrate. The autoantibodies in the patients' sera were directed to: nucleus (speckled type), nucleoli, single stranded (ss) DNA, double stranded (ds) DNA, mitochondria, smooth muscle antigen, gastric parietal cells, thyroid colloid, and thyroid cytoplasma, All sera were used in a 1/10 dilution. Antisera from animal origin (rabbit antisera) were directed to: ds RNA (1/30), sialoglycoprotein from calf brain $(1 / 30)$, human and bovine renal basement membranes $(1 / 80)$, and a keratin fraction from human skin $(1 / 10)$. The appropriate dilutions are given in brackets.

In the indirect IFT the second incubation was performed with FITC-conjugated horse antibodies to human Ig (lot no. PH-17-4-F6, dilution 1/60) or to rabbit Ig (lot no. PK-17-2-F2, dilution 1/70), prepared in our laboratory.

\section{Results}

LIGHT MICROSCOPY, CYTOCHEMISTRY, AND IMMUNOFLUORESCENCE

Fig. 1a shows a cell from the human buccal epithelium with the immunofluorescence pattern of the cytoplasmic granules; they were of different sizes, 0.5-5 $\mu \mathrm{m}$, distributed throughout the cytoplasm, but predominantly around the nucleus. Not only
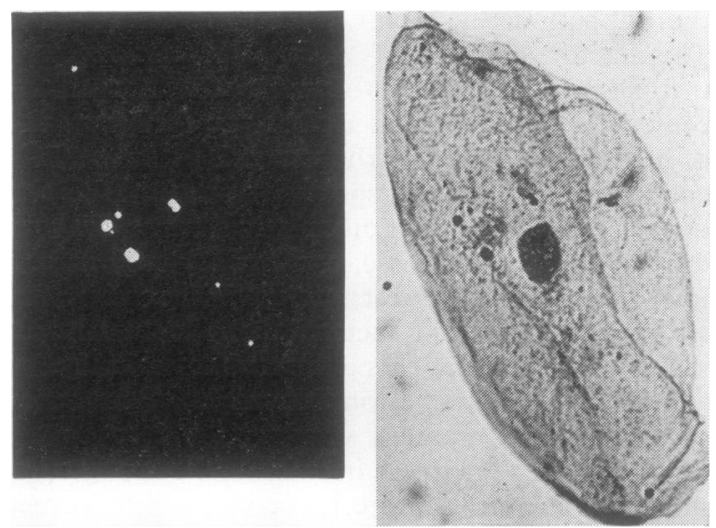

Fig. 1 (a) A human buccal mucosa cell with fluorescent cytoplasmic granules after incubation with an APF positive serum in the indirect IFT. (b) HA staining of the same cell, after the fluorescence technique. The fluorescent granules stain basophilic just like the nucleus $\times 425$. 
the number of positive epithelial cells and the number of granules per cell but also the fluorescence intensity of the granules differed remarkably when incubated with patients' sera that were positive for the APF.

For the chemical identification of the antigenic substrate of the APF several staining procedures were applied on the human buccal mucosa cells. Fig. 1b shows the same cell from Fig. 1a. After the fluorescence technique the cell was stained with HA and the fluorescent granules stained basophilic. Also with other staining methods (MGG and toluidin blue) the granules stained like nuclei. The granules did not stain with ethidium bromide. Thus the granules probably did not contain ds nucleic acids.

Methods were applied in which special chemical components or groups of components are stained: Sudan black (lipids), PAS (certain carbohydrate macromolecules and glycoproteins), MGP (DNA and RNA), Feulgen (DNA) Congo red (amyloid), alcian blue, and azur A (acid mucosubstances), DDD (-SS- and -SH groups). In the staining methods the cytoplasmic granules did not show a positive reaction product.

The epithelial cells were studied for the presence of the enzymes acid phosphatase, nonspecific esterase, and peroxidase, but activity of none of these 3 enzymes could be identified in the granules. With the above mentioned antisera, which were directed to distinct tissues, tissue components, or specially isolated macromolecules, a negative result was obtained concerning the cytoplasmic granules.

\section{OTHER SUBSTRATES}

\section{Human origin}

In cryostat sections of human cheek mucosa, obtained by surgery at the department of paradontology of a dental clinic, several fluorescent granules could be found in the superficial cell layers when incubated with an APF-positive serum (Fig. 2). Cryostat sections of oesophageal mucosa obtained from a child at necropsy showed the same fluorescence pattern. The occurrence of fluorescence on cryostat sections of this oesophageal mucosa correlated very well with the APF test on human buccal mucosa cells. Eight out of 9 RA sera and 9 out of 9 control sera showed the same result in both tests. Oesophageal tissues obtained from other persons at necropsy were received too late to show an intact epithelium.

In a preliminary study on human vaginal cells we used epithelial cells of adults. In preparations of only 2 out of 8 females we could detect a fluorescent pattern of cytoplasmic granules with sera positive for the APF (Fig. 3). With HA and MGG staining

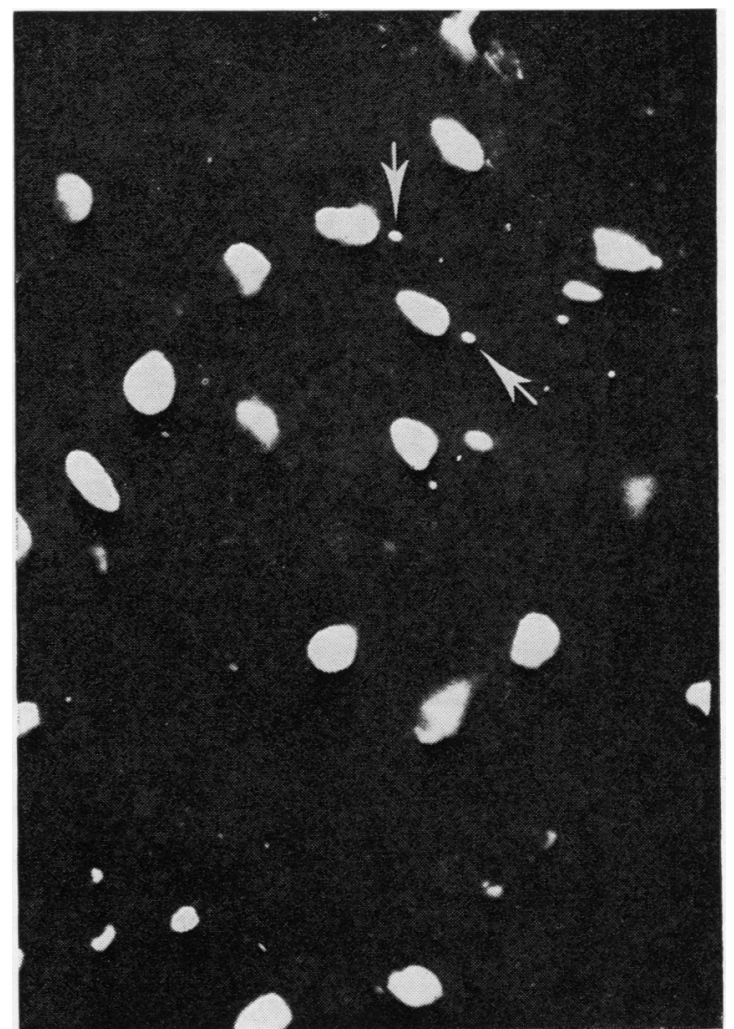

Fig. 2 Cryostat section of human cheek mucosa with (green) fluorescent granules (arrows). The section was incubated with an APF-positive serum in the indirect IFT. Nuclei show a (red) fluorescence due to an ethidium bromide counterstain $\times 590$.

it was evident that basophilic granules were present only in epithelial cells of the individuals positive in the IFT. Thus, at a given moment far from all females obviously possess those peculiar granules. Consequently vaginal cells from newborn babies were used later on, since in those preparations more epithelial cells with cytoplasmic granules could be found. Preparations from 5 babies were tested with different APF-positive and APF-negative sera in the immunofluorescence technique. The results are shown in Table 1. Most of the APFpositive sera showed a positive reaction, while all APF-negative sera gave negative results with vaginal epithelial cells.

Animal origin

Epithelial cells obtained by scraping the oral mucosa of rabbits did not show any cytoplasmic granules in light-microscopical stainings. However, in paraffin sections as well as in cryostat sections of this mucosa 


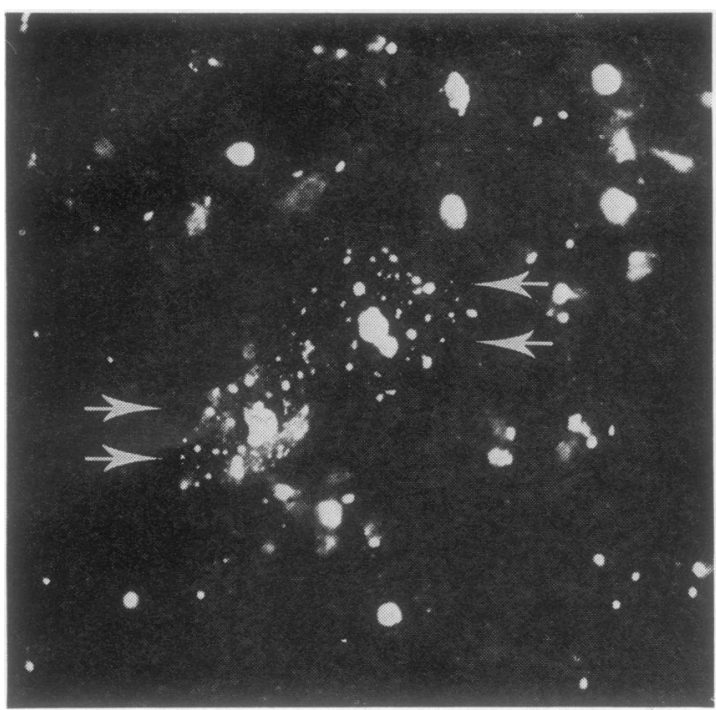

Fig. 3 Human vaginal epithelial cells. incubated with an APF-positive serum in the indirect IFT, showing fluorescent granules (arrows). Nuclei are fluorescent due to an ethidium bromide counterstain $\times 245$.

Table 1 Reaction of granules in human vaginal epithelial cells with APF-positive and APF-negative sera

\begin{tabular}{llllll}
\hline Individual & \multicolumn{2}{c}{$A P F$-positive sera tested } & & \multicolumn{2}{c}{$A P F$-negative sera tested } \\
\cline { 2 - 3 } \cline { 5 - 6 } & Number & Positive & & Number & Positive \\
\hline 1 & 17 & 12 & 5 & 0 \\
2 & 15 & 11 & 5 & 0 \\
3 & 16 & 16 & 5 & 0 \\
4 & 9 & 9 & 3 & 0 \\
5 & 9 & 9 & 3 & 0 \\
\hline
\end{tabular}

many basophilic granules were present in the upper third of the epithelium. Cryostat sections were therefore used in the immunofluorescence technique. Sera positive for the APF gave a strong fluorescence of granules as shown in Fig. 4.

An attempt was made to correlate APF positivity with the occurrence of a positive fluorescence on cryostat sections of the rabbit oral mucosa. When the APF tests on human buccal mucosa cells and on rabbit oral mucosa were compared a statistically significant correlation was found (Table 2). The number of positive sera in the group of normal subjects increased from $4 \%$ to $13 \%$, while the sensitivity of the APF test on rabbit oral mucosa (53\%) was much lower than that of the APF test on human buccal mucosa cells $(79 \%)$ (Table 3$)$. Fluorescent cytoplasmic granules were also found in cryostat sections of rabbit oesophageal mucosa when incubated with sera positive for the APF.

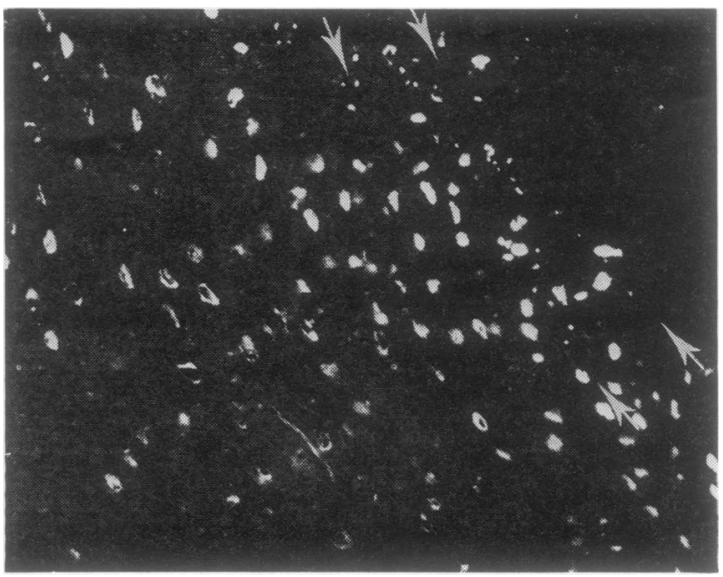

Fig. 4 Cryostat section of rabbit buccal mucosa, incubated with an APF-positive serum in the indirect IFT, showing fluorescent granules in the upper part of the epithelium (layer between arrows). Nuclei show fluorescence due to an ethidium bromide counterstain $\times 180$.

Table 2 Correlation of APF test on different substrates in sera of $R A$ patients

\begin{tabular}{|c|c|c|c|c|}
\hline & & \multicolumn{3}{|c|}{ Rabbit oral mucosa } \\
\hline & & + & - & Total \\
\hline \multirow{2}{*}{$\begin{array}{l}\text { Human } \\
\text { buccal } \\
\text { mucosa } \\
\text { cells }\end{array}$} & + & 47 & 30 & 77 \\
\hline & - & 4 & 16 & 20 \\
\hline Total & & 51 & 46 & 97 \\
\hline
\end{tabular}

$\chi^{2}=10.72 ;$ DF $($ degrees of freedom $)=1 ; P<0.01$

Table 3 Sensitivity of APF test on different substrates in sera from $R A$ patients

\begin{tabular}{|c|c|c|c|c|c|}
\hline \multirow[b]{2}{*}{$\begin{array}{l}\text { Normal subjects } \\
\text { Rheumatoid arthritis }\end{array}$} & \multirow{2}{*}{$\begin{array}{l}\begin{array}{l}\text { Number of } \\
\text { sera }\end{array} \\
96 \\
97\end{array}$} & \multicolumn{2}{|c|}{$\begin{array}{l}\text { APF on } \\
\text { human } \\
\text { buccal } \\
\text { mucosa cells }\end{array}$} & \multicolumn{2}{|c|}{$\begin{array}{l}\text { APF on } \\
\text { rabbit oral } \\
\text { mucosa }\end{array}$} \\
\hline & & $\begin{array}{r}4 \\
77\end{array}$ & $\begin{array}{l}(4 \%) \\
(79 \%)\end{array}$ & $\begin{array}{l}12 \\
51\end{array}$ & $\begin{array}{l}(13 \%) \\
(53 \%)\end{array}$ \\
\hline
\end{tabular}

In correlation experiments 5 out of 41 sera of normal subjects were positive on cryostat sections of rabbit oesophagus, while none of these sera was positive in the APF test. Ten out of 38 RA sera were positive with rabbit oesophagus, while 26 of these sera were positive in the APF test (Table 4). Furthermore there was a considerable variation in results obtained from different oesophagus biopsies.

On cryostat sections of rat, cow, and pig oral mucosa we could not confirm the results obtained 
Table 4 Correlation of APF test on different substrates in sera from $R A$ patients

\begin{tabular}{|c|c|c|c|c|}
\hline & & \multicolumn{3}{|c|}{ Rabbit oesophageal mucosa } \\
\hline & & + & - & Total \\
\hline \multirow{2}{*}{$\begin{array}{l}\text { Human } \\
\text { buccal } \\
\text { mucosa } \\
\text { cells }\end{array}$} & & 8 & 18 & 26 \\
\hline & - & 2 & 10 & 12 \\
\hline Total & & 10 & 28 & 38 \\
\hline
\end{tabular}

$\chi^{2}=0.84 ; D F($ degrees of freedom $)=1 ; P>0 \cdot 10$

from rabbit oral mucosa, although many basophilic granules were present in sections of the rat oral mucosa, as was shown in an HA staining. None of the APF-positive sera tested on these sections showed any fluorescence of the granules.

\section{Discussion}

From previous results ${ }^{2}$ it was stated that the APF antigen was both organ- and species-specific. In our study it appeared that the same or a similar antigen was present in other than human buccal mucosa cells. Because human cheek epithelial cells are used in the test for the presence of APF it was not surprising that antigenic granules were detected in superficial cell layers of cryostat sections of human oral mucosa, or even in cryostat sections of human oesophagus, when these sections were used in the indirect immunofluorescence technique. Other epithelial cells from human origin tested were vaginal epithelial cells. Vaginal cells obtained from newborn babies especially showed antigenic granules. Since this source of epithelial cells was not suitable to serve as the antigenic substrate in the routine APF test, we did not screen so many sera on vaginal epithelial cells, but nevertheless from Table 1 it seems clear that the antigen for the APF is also present in those human vaginal cells.

Cryostat sections of human oesophageal mucosa and of rabbit oral and oesophageal mucosa could serve as an alternative substrate for the APF test. For this reason we screened a number of sera of normal subjects and patients with RA for the presence of antibodies directed to the granules in the human oral epithelial cells and directed to the granules in the superficial epithelial cell layers of these mucosa. Although there exists a very good correlation of the APF test of the human buccal epithelial cells-and that on cryostat sections of human oesophageal mucosa-this latter source could not serve as a suitable substrate because of difficulties in obtaining regularly supply of tissue. It was also found that the APF had a positive correlation with the occurrence of antibodies to granules in the rabbit oral mucosa epithelium, but with cryostat sections more positive sera was found in the group of normal persons while the sensitivity was much lower, $53 \%$ instead of $79 \%$. For rabbit oesophageal mucosa the sensitivity was below $30 \%$, there was no correlation with human buccal cells, and there was too great a variation in the antigenic substrate. We therefore think that the cryostat sections of rabbit mucosa are not suitable as an alternative substrate for the screening of sera for the presence of APF. In cryostat sections of oral mucosa of other species (rat, cow, and pig) we could not demonstrate the antigens by the immunofluorescence technique. In spite of our findings that the APF is not organ- and species-specific the presence of the antigens may be limited to some definite epithelia. For routine performance of the APF test we still advocate the use of human buccal mucosa cell preparations as substrate in the IFT.

The present light-microscopical, cytochemical, and immunofluorescence study of the chemical identity of the granules which contain the antigen for the APF produced only negative results. We therefore cannot confirm the results of Nienhuis ${ }^{9}$ that the granules might contain phosphoglycoproteins or that there might exist a relationship with lysosomes. The chemical nature of the granules and thus of the antigen for the APF remains unresolved.

We express our gratitude to Dr A. van Nieuw Amerongen, Department of Chemical Physiology, Free University, Amsterdam, and to Mr A. L. van Rossum from our laboratory for their gift of the antiserum to sialoglycoprotein from calf brain; to Dr F. W. Bauer, Department of Dermatology, University of Nijmegen, for kindly donating the antihuman keratin antiserum, and to Dr C. J. Lucas from our laboratory for providing the anti-ds RNA antiserum. We are indebted to Dr K. v.d. Velden, Department of Parodontology, University of Amsterdam, for providing the human cheek biopsies, and to Professor Dr H. J. Huisjes, Division of Gynaecology, Department of Medicine, University of Groningen, for supplying the vaginal cell substrates.

\section{References}

1 Sondag-Tschroots I R J M, Aaij C, Smit J W, Felthamp T E W. The antiperinuclear factor. I. The diagnostic significance of the antiperinuclear factor for rheumatoid arthritis. Ann Rheum Dis 1979; 38: 248-251.

2 Nienhuis R L F, Mandema E. A new serum factor in patients with rheumatoid arthritis. The antiperinuclear factor. Ann Rheum Dis 1964; 23: 302-305.

3 Marmont A M, Damassio E E, Berterello C, Rossi F. Studies on the antiperinuclear factor. Arthritis Rheum, 1967; 10: 117-128.

- Wick G, Beutner E H. Quantitative studies of immunofluorescent staining. IV. Indirect immunofluorescence blocking tests with antiperinuclear factors of human and goat origin. Immunology 1970; 18: 821-832.

5 Barnett R J, Seligman A M. Histochemical demonstration 
of sulphydryl and disulfide groups of protein. $J$ Nat Cancer Inst 1954; 14: 769-792.

- Li C Y, Yam L T, Lam K W. Acid phosphatase isoenzyme in human leucocytes in normal and pathologic conditions. $J$ Histochem Cytochem 1970; 18: 473-481.

7 Löffler H. Cytochemischer Nachweis von unspezifischer Esterase in Ausstrichen. Technik B zum Nachweis der Naphtol-AS-Esterase. Klin Wochenschr 1961; 39: 1220.
8 Graham R C, Karnovsky M J. The early stages of absorption of injected horseradish peroxidase in the proximal tubules of mouse kidney: ultrastructural cytochemistry by a new technique. J Histochem $C$ ytochem 1966; 14: 291-302.

9 Nienhuis R L F (1965). Antiperinucleaire factor. Een nieuwe serologische reactie voor de diagnostiek van reumatoïde arthritis. Proefschrift, Groningen. 